\title{
Research on Chinese Animation Film Technology
}

\author{
Jian Luo \\ Chongqing College of Electronic Engineering, Chongqing, 401331
}

Keywords: Animation Film Technology, Chinese Character, Computer Technology

\begin{abstract}
The nation is the public. This sentence is on the artistic style of the classic induction, fully applicable to the creation of animation. Animation used in the creation of many Chinese elements are the essence of the Chinese nation's art, but also popular artistic elements, is the animation to create the most dynamic and most vivid artistic elements. Animation of the Chinese elements refers to the animation in the Chinese-style theme, Chinese-style art (including character modeling, art design, etc.) and the combination of Chinese music. In essence, the pursuit of these elements of Chinese constitutes the Chinese culture or the national style in the animation of the aesthetic pursuit.
\end{abstract}

\section{Introduction}

In 1955, the domestic cartoon "why the crow is black" in the Venice Animation Film Festival award, but the judges mistakenly believe that the Soviet Union works, the matter to the new China's first generation of animation creators on the national style of the problem with personal experience, And then opened the Chinese elements of the innovative animation road. In 1956, the famous animation director Te Wei proposed "to explore the national style of the road" slogan, and pioneering this idea to implement its "pride of generals", and strive to nationalized animation creation practice from the beginning. In 1964, China's film collection of this period of national animation style to explore the set of long film "big temple", in the international response is very good. Animation creation was once in the opening to the blind pursuit of Western style of the trend. China's animation to create more to Japan, Europe and the United States as a template for the animation, from the local culture, to give up their national character, so that the success of animation creation. Chinese style works gradually decline, and ultimately cause China's animation creation in the doldrums. And the adjacent Japanese animation creation, due to the better implementation of its national elements, the emergence of a large number of outstanding works in the international community to obtain a higher status. The difference between the facts proved that the Chinese animation can not be separated from the Chinese elements, to give up their national character it is difficult to have come out of boutique.

In recent years, Chinese elements in China's animation creators gradually get attention. This is mainly due to China's economic strength in the international status and influence continues to expand. In the international market, many of our accustomed to the use of Chinese elements and processed into works, and greatly welcomed by the industry and the general audience, the formation of "Chinese style." This is a great demonstration and proof of the great charm of Chinese elements, but also stimulate and give birth to China's animation creation for the Chinese elements of the importance and use, such as "selling pig" "Huainanzi legend" "lion lion head" and three-dimensional animated short film "drunk flower "And so on, are such representative works. In the domestic animation began to flourish, the number of works more and more today, in improving the quality of animation art at the same time need to be refined, nationalized, large-scale animation to enrich the domestic market. In the emphasis on quality at the same time, how to inherit our animation creation on the Chinese elements and national traditions, highlighting the comprehensive use of Chinese elements, is an indispensable animation in the creation of the meaning. Chinese elements in the animation of the artistic charm of showing a diverse pattern, the Chinese animation and even animation art creation will be a new breakthrough. 


\section{Chinese Elements in the Animation}

Modern media theory that the form is carrying the form of content, the content is the accumulation of the contents of the form, there is no form of content, there is no form of content. In the process of animation creation, the use of Chinese elements should be the combination of content and form to strive for perfection, exquisite. If the Chinese animation from the corresponding content, it will become the absence of the meaning of the empty form; Similarly, the superb form and no Chinese style to support the content, it is only an empty shelf, difficult for everyone love. An excellent animation must be completed in the combination of content and form, thought and art. This combination includes two points: the theme and content of the check, that is, the script of ideas, stories and style to have accurate, scientific predictions, to seize the best expression and expression of Chinese elements of the theme of creation, expression; The technical thinking of the animation, that is, we must weigh the theme and content to achieve the expression, making the realization of the whole piece of the Chinese elements to build a suitable Chinese style, which includes music and pictures, roles and actions, scenes and lights and a series of elements The consideration. These prejudgments and considerations must pay attention to the rational use of Chinese elements, perfect use, can not discard the excellent tradition of animation creation. Only these prejudgments, consider doing well, in order to create a combination of content and form of good animation.

A Chinese story is the soul of a Chinese-style cartoon. The review of the script concept and content is the most important part of the early creation and preparation. Exquisite picture effects and skill is just a good animation of the foundation, must be the story and content as the carrier, the latter is the premise of all the use of the former. An embodiment of the Chinese elements of the excellent animation, first in the theme and the story that content must be "China". The theme selection of Chinese style animation is mostly reflected in the popular aesthetic orientation and value judgment of the public. In the selection of the story, the creators often choose folk tales, idioms, allegories, fairy tales and other themes, but all follow the "text to carry" cultural tradition, that is, it is not a pure form of entertainment, Teach the music means to achieve the transfer of values. This is the content of the Chinese expression. "Rush lion head" story of the climax occurred in the process of robbing the two brothers and sisters suddenly fall into a dangerous paragraph, but ultimately still fall between the two love each other brother and sister feelings, the story is entirely Chinese-style human and moral expression. It crossed the brothers and sisters (competition), when the danger of mutual help, and even sacrifice their own lives, the hope of giving birth to each other, to convey the Chinese-style values. "Huainanzi legend" "three monks" "drunk flower edge" and so on, are drawn from folk tales or legends, the ancient Chinese culture into easy to understand the form of animation, the film's unique ideological and humanistic spirit, are Is a concrete manifestation of Chinese morality and traditional culture. China's animation narrative generally follow the theory of binary opposition, the conflict in the main line, in an attempt to confront the plot to create the audience to judge the value of good and evil. In general, the expression of this theme, but also constitute the cartoon of Chinese elements. Whether it is the early "big temple" "Nezha downtown", or "drunk flower" "Huainanzi legend" "lion lion head", that is, in the form of expression, have inherited the Ming and Qing Dynasties popular novels to the plot Win, twists and turns story features. This will be better integrated into the Chinese elements of the expression of Chinese-style story, making the animation plot ups and downs, and ultimately to achieve the purpose of the text. This is a highlight of Chinese animation expression, but also many of the works of the fascinating success of the mystery.

Cartoon music creation, requires the creator in addition to the composer that has a good composition, equipment, production skills, but also need to have a good sense of drama. Of course, these require foreign animation creators are not lacking. However, the use of very rich folk music, it is the advantage of Chinese animation. Chinese music, such as fighting when the sonorous national percussion, misty misty in the flute, mountains and rivers like Guqin, is very national, is the Chinese elements. China's folk music is pay attention to "the actual situation and health", in the virtual real deal, in the real point to point to the surface to the performance. The use of these national music, in addition to complete the animation of the music requirements, but also can 
contrast the atmosphere, cleverly promote the animation story step by step development, making cartoons marked with a unique Chinese style.

Character modeling is the life of animation, character modeling of the unique, pleasure embodies the success or failure of animation. Animation creators often give their roles different from other animated archetypes of the character and styling features, whether it is deconstructing relationships, or absorbing effective information in the script, the purpose is to accurately and completely from the image design point of view to grasp the contents of the script The However, the expression of the Chinese elements in the animation, the character modeling must be Chinese-style. Early animated film "Heroes of Heaven" character design is very successful. It is different from the same period Disney's styling style, but also clearly different from the traditional Japanese animation style, but with a strong Chinese national style of self-made. The protagonist of the Sun Wukong and Jade Emperor of the shape, are drawn from the classic shape of the traditional Chinese style, and even Dunhuang frescoes and classical drama style has become a "Temple" in the animated characters modeling material. The same period of "Nezha downtown" shape is from the traditional culture to obtain support. "In the role of Chinese cartoon modeling has been successfully used in the visual elements of folk art, the achievements of the" Chinese animation school "brilliant." Animation in the role of character modeling that the character of the Chinese elements of the expression of many outstanding cartoon So the secret of success.

"Lion head" in character modeling this point is very successful. In the short film, whether it is the main role (lion sisters) or supporting role (such as drummer, spectators), its shape will be used with Chinese characteristics of clothing modeling and hair design, completely different from that country, national "big animation" The As a result of the success of the characters, a sister appears to be naive naughty, brother art tall and bold, nervous spectator and season, stout drummer are impressive; two because of its use of the unique Chinese traditional elements, are the only, Vivid, with a visual freshness, aesthetic pleasure. This kind of nationalized art design, in the animation creation, of course, not only limited to the character modeling, but also contains the background design, props modeling design and many other aspects. "Lion lion head" picture background design is pure Chinese-style, such as the performance of the Quartet restaurant, brother and sister living on the walls of the Chinese painting, such as props modeling lion head, gongs and drums, rolling tripod, and so on, are Chinese elements Exquisite use, to build a concentrated traditional culture of the Chinese world. Although the play is not directly dialogue, the traditional picture background has passed out of the character of the character and the role of the Chinese environment.

The same originality, as well as Chinese animation short film "sell pigs". It selected a very representative of the original eco-tourism in northern Shaanxi, Shaanxi and other traditional Chinese folk music for the background music, through the picture and music tacit understanding to show a northern Shaanxi Loess Plateau style background. The success of this short film is entirely due to its unique picture design style. Unique picture design and unique background music, so that the audience naturally entered a combination of sound and picture of the world, the northern Shaanxi folk, yellow land is full of freshness.

\section{Conclusion}

Animation in the design of art, we must pay attention to the creative use of Chinese elements, but should not be modeled on the Chinese elements must be complete and fit the content of innovation. The design of these art images, in the whole story should be a series of. Creators should not only focus on a single image, but also focus on the content and form of the integrity of Chinese elements. Therefore, we should pay attention to the overall art modeling, but also the animation of the role of the relationship between the role of the design, the plot of the contradictory relationship, logical association and so on one by one stroke in order to achieve the artistic completion and success.

\section{References}

[1] Li Xi. China's regional culture in the traditional animation works [J]. Art Technology, 2016 (01) 
[2] Pan Honglian. Dynamic visual art performance in graphic animation [J]. Journal of Chengdu University (Social Science Edition), 2015 (02)

[3] Wang Yan. Study on the Artistic Expression Method of Animation ontology in Motion Graphic Design [J] .Art and Design (Theory), 2015 (06)

[4] Zong Xuemei. Interpretation of graphics animation for the visual communication language reconstruction [J]. Technology wind, 2015 (22)

[5] Wang Shangshang. Sports graphics animation teaching and research [J]. Science and Technology Communication, 2014 (02) 